\title{
Pediatric HIV care and treatment services in Tanzania: implications for survival
}

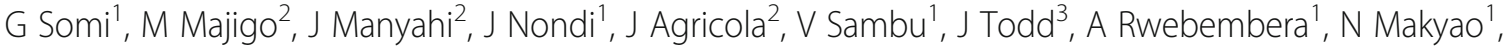 \\ A Ramadhani ${ }^{1}$ and MIN Matee ${ }^{2^{*}}$
}

\begin{abstract}
Background: Improving child survival for HIV-infected children remains an important health agenda. We present progress regarding care and treatment services to HIV infected children in Tanzania.

Methods: The National AIDS Control Programme Care and Treatment (CTC 2) database was used to obtain information of all children aged 0-14yearsenrolled in the HIV Care and Treatment Program between January 2011 and December 2014. We assessed eligibility for ART, time from enrolment to ART initiation, nutritional status, and mortality using Kaplan-Meier methods.

Results: A total of 29,531 (14,304 boys and 15,227 girls) ART-naive children aged 0-14 years were enrolled during the period, approximately 6700 to 8000 children per year. The male to female ratio was 48:50. At enrolment 72\% were eligible for ART, 2-3\% of children were positive for TB, and 2-4\% were severely malnourished.

Between 2011 and 2014, 2368 (8\%) died, 9243 (31\%) were Lost to Follow-up and 17,920 (61\%) were on care or ART. The probability of death was 31\% (95\% Cl 26-35), 43\% (40-47), 52\% (49-55) and 61\% (58-64) by 1,2, 5 and 10 years of age, respectively. The hazard of death was greatest at very young ages ( $<2$ years old), and decreased sharply by 4 years old. Children who were on ART had around 10-15\% higher survival over time.

Conclusions: Significant progress has been made regarding provision of paediatric HIV care and treatment in Tanzania. On average 7000 children are enrolled annually, and that approximately two thirds of children diagnosed under the age of 2 years were initiated on ART within a month. Provision of ART as soon as the child is diagnosed is the biggest factor in improving survival. However we noted that i) most children had advanced disease at the time of enrolment ii) approximately two-thirds of children were missing a baseline CD4 measurement and only $35 \%$ of children had either a CD4 count or percentage recorded, indicating limited access to CD4 testing services, and iii) $31 \%$ were lost to follow-up (LTFU).

These challenges need to be addressed to improve early detection, enrolment and retention of HIV-infected children into care and improve documentation of services offered.
\end{abstract}

Keywords: Children, HIV, Enrolment, ART, Care, Mortality, Survival

\section{Background}

The 2015 Spectrum model estimates 142,000 Tanzanian children, under the age of 15 years, are infected with human immunodeficiency virus (HIV) [1], and current guidelines state all should be given Antiretroviral Therapy (ART) [2]. Without ART approximately $50 \%$ of HIV infected children die before the age of two, and one-

\footnotetext{
* Correspondence: mateemecky@yahoo.com

${ }^{2}$ Department of Microbiology and Immunology, School of Medicine,

Muhimbili University of Health and Allied Sciences, Mwanza, Tanzania

Full list of author information is available at the end of the article
}

third of those who survive past two die before 5 years of age [3]. Improving child survival for HIV exposed and infected children remains an important agenda in Tanzania [4]. Promoting universal access to available HIV care and treatment services is important for improving survival of HIV-infected individuals, especially children [5].

The encouraging success of ART, which includes effective prevention of mother-to-child transmission, has led to ambitious calls to eliminate HIV as a public health threat by 2030 [6]. Achievement of these goals, including 
the United Nations Programme on HIV/AIDS (UNAIDS) 90-90-90 targets, which aim to have 90\% of people living with HIV know their status, $90 \%$ of those detected treated with ART, and 90\% of those receiving treatment achieving viral load suppression [7], requires a coordinated global scale-up of prevention programmes, pre-exposure prophylaxis (PrEP), and detection and treatment programmes [8].

On its part, the government of the United Republic of Tanzania has laid out goals aiming at zero new HIV infections, zero discrimination and zero HIV related deaths in the population, including children, by 2017 [9]. These goals guide interventions that contribute to improving access to HIV services, especially for vulnerable groups like children.

It is well known that universal access to HIV care and treatment services contributes to improved quality of life, and thus economic, social and political development of society [10], which is in keeping with the United $\mathrm{Na}$ tions (UN) sustainable goals number 3 [11]. The National AIDS Control Programme (NACP) in Tanzania is aiming at providing antiretroviral medicines (ARVs) to People Living with HIV and AIDS (PLHIV). The main focus is to improve access to ART services in order to reduce HIV related morbidity and mortality, especially among children. Due to this, Ministry of Health in Tanzania requires that paediatric HIV statistics be made available and utilized for policy and decision-making. This report summarizes progress made in providing HIV care and treatment services to children in Tanzania and highlights challenges in achieving universal access for ART to HIV-infected children. The information in this report contributes to the monitoring of Pediatric HIV and AIDS program in Tanzania.

\section{Methods}

\section{Design, setting and population}

This was a descriptive analytical study based on NACP data of children aged 0-14 that was routinely collected from 740 HIV care and treatment service delivery clinics between 2011 and 2014 and archived in the NACP database, where data was extracted.

\section{Data management and analysis}

Primary data generated in the HIV care and treatment clinics (CTC) was captured on facility-held information collection tools designated as CTC-2 card. This was submitted on quarterly basis to national level at NACP in either paper form or electronic system, and subsequently entered in the national care and treatment database designated as CTC-3. The CTC-3 database contains both patient-level section (CTC-3 Macro), exported electronically from clinics using an electronic CTC-2 database and aggregate-level section (CTC-3) that contains data receive quarterly summary reports either paper based or extracted from the CTC-2 data. Data analysis was performed using Stata version 14 [12].

\section{Eligibility for ART}

We determined eligibility of children for ART based on WHO staging or CD4 results and estimated the time from enrolment to ART initiation. Results for eligibility for ART are restricted to 2012 onwards, since the national guidelines changed in 2012, which advocate initiation of ART regardless of World Health Organization (WHO) clinical stage and CD4 cell count [13]. The previous eligibility criteria, before the 2012 guidelines, was CD $4<25 \%$ or WHO stage 3 and 4 . A window of -90 to +30 days relative to the date of ART start was allowed to capture characteristics at ART start choosing that closest measurement to ART start, with preference for before.

\section{Assessment of nutritional status}

Nutritional status of children was assessed over time using weight and length or height for age. The nutrition status was translated using Z-score criteria of Weight for age and weight for length/Height. Time was categorized into 3 monthly periods and the highest non-missing nutritional status for each child in each 3 months period was used.

\section{Estimation of mortality}

Mortality was estimated using Kaplan-Meier methods from date of birth, with entry into the risk set from the time of enrolment through death. Lost to follow up (LTFU) was defined if a child was not seen within the 6 months before the end of December 2014 and censored at their last visit date. Children who had not died and were not defined as LTFU were considered to be in follow up through to the analysis censoring date of 31 December 2014 and were censored at that time. Children were defined as No Longer On Treatment (NLOT) if they had either died or were LTFU.

\section{Ethical consideration and approval}

Data used in this analysis was collected routinely by health facilities providing HIV care and treatment services following the National Guidelines for HIV Care and Treatment, in which ethical issues are strongly advocated. Permission to analyse and publish this data was granted by the Ministry of Health, Community Development, Gender, Elderly and Children (MoHCDGEC). Management of the data was under strict supervision the Epidemiology Unit of NACP.

\section{Results}

Children characteristics at CTC enrolment

A total of 29,531 (14,304 (48\%) boys and 15,227 (52\%) girls) ART-naive children aged 0-14 years were enrolled 
between 2011 and 2014, which is approximately 6700 to 8000 children per year. The characteristics of enrolees are shown in Table 1.

Of the 29,531 children enrolled in care, a total of 10,390 (35\%) were in WHO stage III and 3196 (11\%) were in WHO stage IV (Table 1). The proportion of children with CD4 count $<50$ cells $/ \mathrm{mm} 3$ decreased in 2014 compared to earlier years $(4.3 \%$ in 2014 versus $5.9 \%$ overall). However, approximately two-thirds of children across all years were missing a baseline CD4 absolute count. The proportion of children missing CD4 percentage data was even higher, at nearly $100 \%$ overall. Only $35 \%$ of children had either a CD4 count or percentage recorded.

The most common referral point was voluntary counselling and testing (VCT) (18\% overall), followed by provider initiated testing and counselling (PITC) (12\%). However, $65 \%$ of children did not have their referral point recorded (Table 2).
Approximately $2-3 \%$ of children were identified at enrolment as being positive for TB and this was fairly constant across the years (Table 2). TB screening was done using a standardized TB screening tool (annex). All children $<5$ years old are given cotrimoxazole and for $>5$ years with CD4 cell count below 350 . The proportion of children on cotrimoxazole over the years has also remained fairly constant, at $70-74 \%$. In earlier years, the nutritional status of children at enrolment was not consistently captured (22\% missing in 2011 and 50\% missing in 2012). In 2014, the missing data was a lot lower $(10 \%)$. Across all years, the majority of children were not malnourished, with only $2-4 \%$ recorded as being severe malnourished (Table 2).

Eligibility at enrolment and time to starting ART

Among the 21,503 children enrolled in 2012-2014, 15,522 (72\%) were eligible for ART from enrolment (Table 3). However, 4624 (22\%) had unknown eligibility,

Table 1 Baseline characteristics of 29,531 children enrolled into HIV care services between 2011 and 2014

\begin{tabular}{|c|c|c|c|c|c|c|}
\hline & & 2011 & 2012 & 2013 & 2014 & Total \\
\hline Total (row \%) & & 8028 (27.2\%) & 6727 (22.8\%) & 7171 (24.3\%) & 7605 (25.8\%) & $29,531(100 \%)$ \\
\hline \multirow[t]{2}{*}{ Sex } & Male & 3913 (48.7\%) & 3262 (48.5\%) & 3418 (47.7\%) & 3711 (48.8\%) & $14,304(48.4 \%)$ \\
\hline & Female & 4115 (51.3\%) & 3465 (51.5\%) & 3753 (52.3\%) & 3894 (51.2\%) & $15,227(51.6 \%)$ \\
\hline \multirow[t]{5}{*}{ WHO stage } & Stage I & 2083 (25.9\%) & 1732 (25.7\%) & 1685 (23.5\%) & 1713 (22.5\%) & 7213 (24.4\%) \\
\hline & Stage II & 2417 (30.1\%) & 1838 (27.3\%) & 1934 (27.0\%) & 2045 (26.9\%) & 8234 (27.9\%) \\
\hline & Stage III & 2420 (30.1\%) & 2240 (33.3\%) & 2686 (37.5\%) & 3044 (40.0\%) & $10,390(35.2 \%)$ \\
\hline & Stage IV & 917 (11.4\%) & 805 (12.0\%) & $768(10.7 \%)$ & 706 (9.3\%) & 3196 (10.8\%) \\
\hline & Missing & 191 (2.4\%) & $112(1.7 \%)$ & $98(1.4 \%)$ & $97(1.3 \%)$ & 498 (1.7\%) \\
\hline \multirow[t]{5}{*}{ Weight, kg } & $<10$ & $2121(26.4 \%)$ & 1850 (27.5\%) & 1845 (25.7\%) & 1850 (24.3\%) & 7666 (26.0\%) \\
\hline & $10-<20$ & 3129 (39.0\%) & 2542 (37.8\%) & 2855 (39.8\%) & 3003 (39.5\%) & $11,529(39.0 \%)$ \\
\hline & $20-<30$ & 1582 (19.7\%) & 1316 (19.6\%) & 1442 (20.1\%) & 1532 (20.1\%) & 5872 (19.9\%) \\
\hline & $>=30$ & 934 (11.6\%) & $814(12.1 \%)$ & $801(11.2 \%)$ & $933(12.3 \%)$ & 3482 (11.8\%) \\
\hline & Missing & 262 (3.3\%) & 205 (3.0\%) & 228 (3.2\%) & 287 (3.8\%) & 982 (3.3\%) \\
\hline \multirow[t]{4}{*}{ CD4 cell count, cells/mm3 } & $<50$ & $488(6.1 \%)$ & $467(6.9 \%)$ & $460(6.4 \%)$ & $330(4.3 \%)$ & $1745(5.9 \%)$ \\
\hline & 50-199 & $627(7.8 \%)$ & $688(10.2 \%)$ & $710(9.9 \%)$ & $681(9.0 \%)$ & $2706(9.2 \%)$ \\
\hline & $>=200$ & $1404(17.5 \%)$ & $1444(21.5 \%)$ & $1472(20.5 \%)$ & $1444(19.0 \%)$ & $5764(19.5 \%)$ \\
\hline & Missing & $5509(68.6 \%)$ & $4128(61.4 \%)$ & $4529(63.2 \%)$ & $5150(67.7 \%)$ & $19,316(65.4 \%)$ \\
\hline \multirow[t]{3}{*}{ CD4 percentage, $\%$} & $<25$ & $63(0.8 \%)$ & $21(0.3 \%)$ & $0(0.0 \%)$ & $0(0.0 \%)$ & $84(0.3 \%)$ \\
\hline & $>=25$ & $20(0.2 \%)$ & $4(0.1 \%)$ & $0(0.0 \%)$ & $0(0.0 \%)$ & $24(0.1 \%)$ \\
\hline & Missing & $7945(99.0 \%)$ & $6702(99.6 \%)$ & $7171(100.0 \%)$ & 7605 (100.0\%) & $29,423(99.6 \%)$ \\
\hline \multirow[t]{2}{*}{ Measurement of CD4 count or percent } & Have at least one & $2577(32.1 \%)$ & 2619 (38.9\%) & $2642(36.8 \%)$ & $2455(32.3 \%)$ & 10,293 (34.9\%) \\
\hline & Missing both & $5451(67.9 \%)$ & $4108(61.1 \%)$ & 4529 (63.2\%) & 5150 (67.7\%) & $19,238(65.1 \%)$ \\
\hline \multirow[t]{5}{*}{ Facility type } & Dispensary & 815 (10.2\%) & $929(13.8 \%)$ & $1206(16.8 \%)$ & 1477 (19.4\%) & 4427 (15.0\%) \\
\hline & Health centre & 2395 (29.8\%) & 2129 (31.6\%) & 2418 (33.7\%) & 2750 (36.2\%) & 9692 (32.8\%) \\
\hline & Hospital & 4366 (54.4\%) & 3354 (49.9\%) & 3297 (46.0\%) & 3155 (41.5\%) & $14,172(48.0 \%)$ \\
\hline & Other & 437 (5.4\%) & 301 (4.5\%) & 224 (3.1\%) & 199 (2.6\%) & 1161 (3.9\%) \\
\hline & Missing & 15 (0.2\%) & 14 (0.2\%) & $26(0.4 \%)$ & 24 (0.3\%) & 79 (0.3\%) \\
\hline
\end{tabular}


Table 2 Referral sources, prophylaxis and nutritional status of 29,531 children enrolled into care between 2011 and 2014

\begin{tabular}{|c|c|c|c|c|c|c|}
\hline \multirow[t]{6}{*}{ Referral source } & & 2011 & 2012 & 2013 & 2014 & Total \\
\hline & $\mathrm{HBC}$ & $48(0.6 \%)$ & $28(0.4 \%)$ & $38(0.5 \%)$ & $23(0.3 \%)$ & $137(0.5 \%)$ \\
\hline & PITC & 894 (11.1\%) & 748 (11.1\%) & 934 (13.0\%) & 1040 (13.7\%) & 3616 (12.2\%) \\
\hline & PMTCT & $330(4.1 \%)$ & $310(4.6 \%)$ & $285(4.0 \%)$ & $364(4.8 \%)$ & 1289 (4.4\%) \\
\hline & $\mathrm{VCT}$ & 1524 (19.0\%) & 1329 (19.8\%) & $1287(17.9 \%)$ & $1284(16.9 \%)$ & $5424(18.4 \%)$ \\
\hline & Missing & $5232(65.2 \%)$ & 4312 (64.1\%) & $4627(64.5 \%)$ & $4894(64.4 \%)$ & $19,065(64.6 \%)$ \\
\hline \multirow[t]{3}{*}{ Positive for TB } & No & 27,658 (93.7\%) & 7359 (91.7\%) & $6251(92.9 \%)$ & $6780(94.5 \%)$ & 7268 (95.6\%) \\
\hline & Yes & 672 (2.3\%) & $117(1.5 \%)$ & $149(2.2 \%)$ & $211(2.9 \%)$ & 195 (2.6\%) \\
\hline & Missing & 1201 (4.1\%) & $552(6.9 \%)$ & 327 (4.9\%) & $180(2.5 \%)$ & $142(1.9 \%)$ \\
\hline \multirow[t]{2}{*}{ Cotrimoxazole } & No & 7977 (27.0\%) & $2264(28.2 \%)$ & $2026(30.1 \%)$ & 1835 (25.6\%) & 1852 (24.4\%) \\
\hline & Yes & $21,554(73.0 \%)$ & $5764(71.8 \%)$ & 4701 (69.9\%) & $5336(74.4 \%)$ & 5753 (75.6\%) \\
\hline \multirow[t]{5}{*}{ Malnourished } & No & 19,172 (64.9\%) & 3370 (42.0\%) & $4540(67.5 \%)$ & $5272(73.5 \%)$ & 5990 (78.8\%) \\
\hline & Mild & $3(0.0 \%)$ & $3(0.0 \%)$ & $0(0.0 \%)$ & $0(0.0 \%)$ & $0(0.0 \%)$ \\
\hline & Moderate & 3005 (10.2\%) & $453(5.6 \%)$ & $806(12.0 \%)$ & 911 (12.7\%) & 835 (11.0\%) \\
\hline & Severe & $906(3.1 \%)$ & 158 (2.0\%) & $268(4.0 \%)$ & 259 (3.6\%) & $221(2.9 \%)$ \\
\hline & Missing & 6445 (21.8\%) & 4044 (50.4\%) & $1113(16.5 \%)$ & 729 (10.2\%) & $559(7.4 \%)$ \\
\hline
\end{tabular}

mainly due to either being categorized as WHO stage I or II or missing CD4 count or percentage. The proportion with unknown eligibility was slightly lower among older compared to younger children except for $<2$ year olds, who were all eligible for treatment initiation regardless of WHO staging or CD4 results.

Among $<2$ year olds, who should all start treatment immediately regardless of WHO stage or CD4 results, $41 \%$ initiated treatment on the day of enrolment into CTC care, and a further $24 \%$ initiated within 1 month of enrolment (Table 4). However, around 7\% started treatment $>3$ months after enrolment, and $21 \%$ had not started treatment at all.

\section{ART initiation by age}

A total of 15,805 children were observed to initiate ART by the end of December 2014 (Table 4). The proportion by age were $13 \%$ aged $<1$ year, $36.2 \%$ aged $1-4$ years, $26.6 \%$ aged $5-9$ years, $20.6 \%$ aged $10-14$ years and $<1 \%$ aged $14+$ years (Table 5).

\section{Nutritional status}

Figure 1 shows the nutritional status of children over time from ART initiation. The declining bars show that fewer children are being followed up for long after ART initiation. Overall most children were not malnourished, and there was little severe malnutrition observed after 3 months on ART.

\section{Mortality of children}

Among 29,531 children enrolled in 2011-2014, 2368 (8\%) were known to have died, 9243 (31\%) were considered LTFU and 17,920 (61\%) were still under active follow up. Fig. 2 shows the survival probability over age. The probability of death by 1 year of age was $31 \%$ (95\% CI 26-35), by 2 years of age was $43 \%$ (40-47), by 5 years of age was $52 \%(49-55)$ and by 10 years of age was $61 \%$ (58-64). The hazard of death was greatest at very young ages $(<2$ years old), decreased sharply by 4 years old and then plateaued, with relatively constant hazard from 4 to 10 years old (Fig. 3 ).

Children who were on ART had around 10-15\% higher survival over time (Fig. 4). The hazard was substantially higher among younger chilren not on ART compared to those on ART (Fig. 5). However, from 4 years of age onwards, there was little difference in the hazards between children irrespective of ART status.

\section{Discussion}

Our results show that the number of children enrolled into HIV care and treatment programme per year is

Table 3 Eligibility for ART initiation by age at enrolment

\begin{tabular}{llllll}
\hline Age category II, years & $<2$ & $2-5$ & $6-9$ & $10-14$ & Total \\
\hline Eligible & $6073(100 \%)$ & $3840(61 \%)$ & $2855(60 \%)$ & $2754(63 \%)$ & $15,522(72 \%)$ \\
Not eligible & 0 & $317(5 \%)$ & $603(13 \%)$ & $437(10 \%)$ & $1327(6 \%)$ \\
Unknown eligibility & 0 & $2088(33 \%)$ & $1326(28 \%)$ & $1210(27 \%)$ & $4624(22 \%)$ \\
Total & $6073(100 \%)$ & $6245(100 \%)$ & $4784(100 \%)$ & $4401(100 \%)$ & $21,503(100 \%)$ \\
\hline
\end{tabular}


Table 4 Time from enrolment to ART initiation by age

\begin{tabular}{|c|c|c|c|c|c|}
\hline & $<2$ & $2-5$ & $6-9$ & $10-14$ & Total \\
\hline Enrolment & $2468(40.6 \%)$ & 1398 (22.4\%) & $874(18.3 \%)$ & $753(17.1 \%)$ & $5493(25.5 \%)$ \\
\hline Within 1 month & 1439 (23.7\%) & $1583(25.3 \%)$ & $1318(27.6 \%)$ & 1468 (33.4\%) & 5808 (27.0\%) \\
\hline Within 2 months & $316(5.2 \%)$ & $426(6.8 \%)$ & $346(7.2 \%)$ & $330(7.5 \%)$ & $1418(6.6 \%)$ \\
\hline Within 3 months & $150(2.5 \%)$ & 185 (3.0\%) & $148(3.1 \%)$ & 172 (3.9\%) & 655 (3.0\%) \\
\hline Within 6 months & $196(3.2 \%)$ & $288(4.6 \%)$ & $270(5.6 \%)$ & $200(4.5 \%)$ & 954 (4.4\%) \\
\hline Within 12 months & $142(2.3 \%)$ & $275(4.4 \%)$ & $239(5.0 \%)$ & 195 (4.4\%) & $851(4.0 \%)$ \\
\hline$>12$ months & $90(1.5 \%)$ & $220(3.5 \%)$ & $179(3.7 \%)$ & 137 (3.1\%) & $626(2.9 \%)$ \\
\hline Not yet started & 1272 (20.9\%) & 1870 (29.9\%) & $1410(29.5 \%)$ & $1146(26.0 \%)$ & $5698(26.5 \%)$ \\
\hline Total & 6073 (100\%) & 6245 (100\%) & 4784 (100\%) & 4401 (100\%) & $21,503(100 \%)$ \\
\hline
\end{tabular}

between 6700 and 8000 and that the proportion of girls is slightly higher compared to boys. Almost $72 \%$ of the enrolled children were eligible for ART at the time of enrolment, and that almost half $(46 \%)$ were in WHO stages III and IV, indicative of advanced disease stage. Mortality rate among the enrolees was about $8 \%$, and the hazard was substantially higher among younger children not on ART compared to those on ART.

Provision of ART as soon as the child is diagnosed is the biggest factor in improving survival, with a hazard of mortality in the first year of life, at $15 \%$ for children on ART, compared to $26 \%$ for children not on ART. Children who were on ART had around $10-15 \%$ higher survival over time. However, from 4 years of age onwards, there was little difference in the hazards between children irrespective of ART status. It is likely that children who reach older ages without having started treatment are likely to be be "long term non-progressors", refering to individuals who are infected with HIV, but maintain a CD4 count greater than 500 without antiretroviral therapy with a detectable viral load [14].

The benefits of ART observed in this study have been demonstrated in several studies showing significant reduction mortality with early ART initiation, within the first 12 weeks of life [15-23], accompanied with a greater than $90 \%$ probability of survival into adulthood [24].

Our study revealed a number of significant challenges that need considerable attention by National AIDS
Control Programme and other stakeholders involved in the provision of paediatric HIV care and treatment services in Tanzania. We noted that i) most children have advanced disease at the time of enrolment ii) approximately two-thirds of children were missing a baseline CD4 measurement and only $35 \%$ of children had either a CD4 count or percentage recorded, indicating limited access to CD4 testing services, and iii) $31 \%$ were lost to follow-up (LTFU).

It is therefore a critical public health priority to address these challenges for a successful expansion of paediatric HIV care and treatment services in Tanzania. Strategies for early diagnosis of HIV-infected children and linking them to care and treatment services are essential. Besides this, minimizing the current attrition rates, which have also been observed in clinical settings across all HIV programs in Africa, with overall attrition rates ranging from $10 \%$ to more than $50 \%$ at 24 months [25-30], mainly because of loss to follow-up (LTFU) or AIDS-related death [27, 31]. One possible explanation of the high rates of LTFU could associated with the quality of the data collection and reporting systems, which is a common challenge of health information systems in resource-limited settings [32-34]. Improving capacity for systematic monitoring and accurate reporting may reduce the number of patients LTFU, particularly for sites that rely on paper-based monitoring systems.

Despite these challenges it was encouraging to note that majority of children had good nutrition status, with

Table 5 ART initiation by age

\begin{tabular}{llllll}
\hline & & 2012 & 2013 & 2014 & Total \\
\hline Age category I & Age & $3876(24.5 \%)$ & $5488(34.7 \%)$ & $6441(40.8 \%)$ & $15,805(100 \%)$ \\
& $<1$ & $631(16.3 \%)$ & $681(12.4 \%)$ & $745(11.6 \%)$ & $2057(13.0 \%)$ \\
& $1-4$ & $1403(36.2 \%)$ & $2065(37.6 \%)$ & $2506(38.9 \%)$ & $5974(37.8 \%)$ \\
& $5-9$ & $1031(26.6 \%)$ & $1562(28.5 \%)$ & $1764(27.4 \%)$ & $4357(27.6 \%)$ \\
& $10-14$ & $797(20.6 \%)$ & $1146(20.9 \%)$ & $1363(21.2 \%)$ & $3306(20.9 \%)$ \\
& $>14^{a}$ & $14(0.4 \%)$ & $34(0.6 \%)$ & $63(1.0 \%)$ & $111(0.7 \%)$ \\
\hline
\end{tabular}

\footnotetext{
${ }^{a}$ Captured aged $<15$ years at enrolment but became $>14$ years old before starting treatment
} 


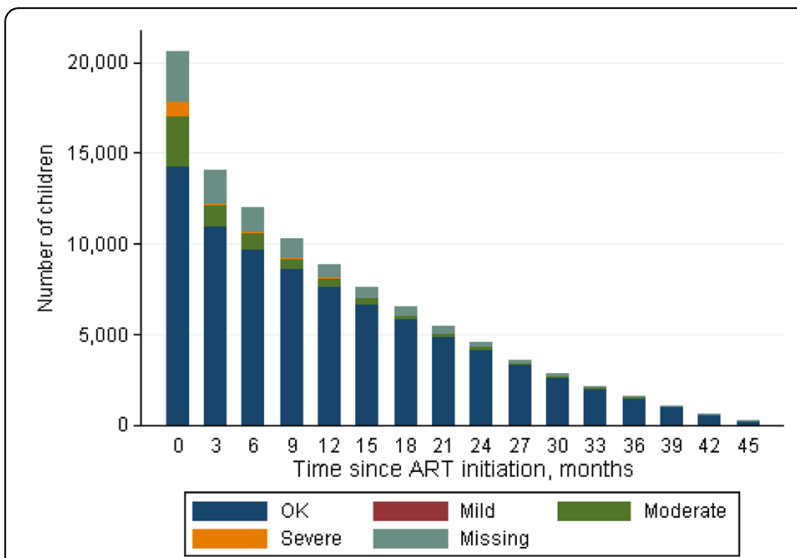

Fig. 1 Nutritional status of children over time from ART initiation

only $2-4 \%$ of children severely malnourished and that nutritional status improved with time on ART. Furthermore, only $2-3 \%$ of children were diagnosed with TB at the time of enrolment and that the proportion of children on Cotrimoxazole was high (70-74\%).

\section{Limitations of the study}

This report has analysed a large amount of data from across Tanzania, but there are several limitations to our findings. One limitation is that the data come from the electronic, CTC database, which is used in the larger and better run clinics. The situation reported here might not be the same in smaller health facilities that have not provided electronic data. Secondly the data are dependent on the self-reporting of conditions (such as opportunistic infections) by patients, and the recording of such data by clinicians and nurses. The amount of missing data has been reduced over the past 5 years but it is still a problem.

We have used basic statistical methods to analyse these data. Some of the assumptions around independence may not be valid in the analysis of these data,

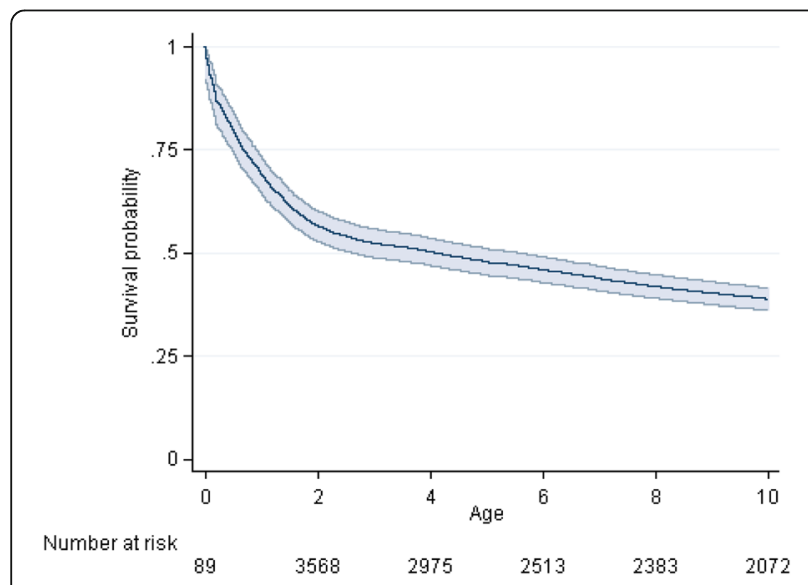

Fig. 2 Survival of HIV positive children from birth (age in years)

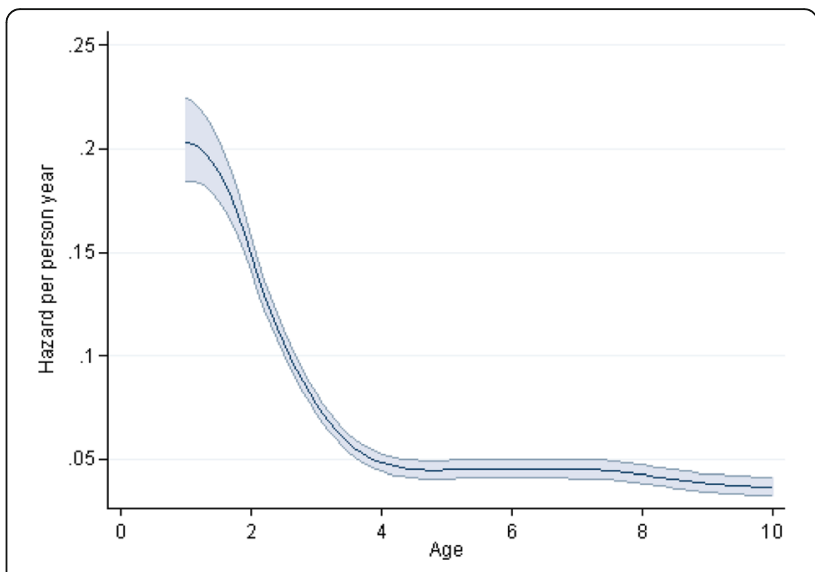

Fig. 3 Hazard from birth in HIV positive children (age in years)

especially in the treatment of missing data (which is likely to be correlated with the outcomes). We have used a competing risks analysis of the mortality pre-ART, which is a first step in acknowledging these concerns about the use of basic statistical methods. However further work needs to be done about the theoretical underpinnings of the statistical methods used for the analysis of routinely collected data.

Despite its limitations, this review has provided some insights in to the achievements and gaps in clinical services for paediatric HIV care and treatment in Tanzania and does suggest areas that could be strengthened to improve these services.

\section{Conclusions}

Significant progress has been made regarding provision of paediatric HIV care and treatment in Tanzania. On average 7000 children are enrolled annually, and that approximately two thirds of children diagnosed under the age of 2 years were initiated on ART within a month. Provision of ART as soon as the child is diagnosed is the

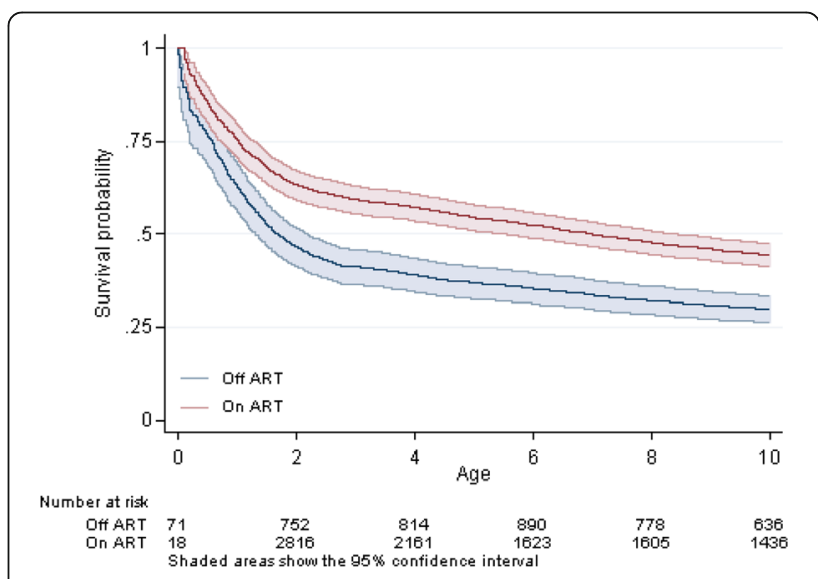

Fig. 4 Survival from birth, in HIV positive children, by ART status 


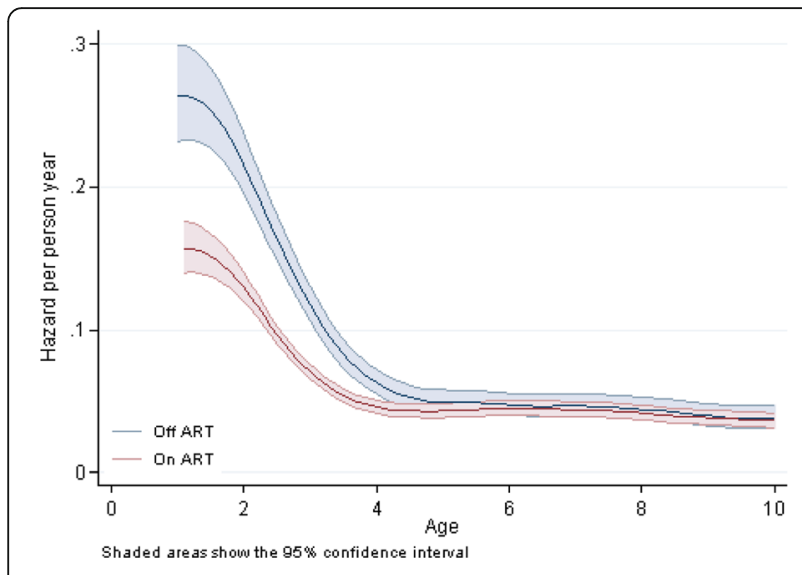

Fig. 5 Hazard from birth, in HIV positive children, by ART status

biggest factor in improving survival, with a hazard of mortality in the first year of life, at $15 \%$ for children on ART, compared to $26 \%$ for children not on ART. However we noted that i) most children had advanced disease at the time of enrolment ii) approximately twothirds of children were missing a baseline CD4 measurement and only $35 \%$ of children had either a CD4 count or percentage recorded, indicating limited access to CD4 testing services, and iii) $31 \%$ were lost to follow-up (LTFU). These challenges underscore the need for more aggressive strategies to increase enrolment and retention of children in such settings. Evidently more work is needed to link HIV-infected children to HIV services.

\section{Abbreviations \\ ART: Anti-retroviral Therapy; CD4: Cluster of Differentiation 4; CDC: Centres for Disease Control; CTC: Care and Treatment Clinic; HIV: Human Immunodeficiency Virus; LTFU: Lost To Follow Up; NACP: National AIDS Control Programme; NIMR: National Institute for Medical Research; NLOT: No Longer On Treatment; UNAIDS: United Nations Programme on HIV/AIDS; WHO: World Health Organization}

\section{Acknowledgements}

We wish to acknowledge the contribution of all health care providers at the Regional, District and Health care facility levels in generating and compilation of data at their respective levels of service delivery. We also wish to thank all staff from the Epidemiology Unit of the National AIDS Control Programme for the eventual compilation and analysis of data at national level.

\section{Funding}

Funding came from The Ministry of Health, Community Development, Gender, Elderly and Children (MCDGC) through National AIDS Control Programme (NACP) with further support from Centres for Disease Control (CDC) and World Health Organization (WHO)

\section{Availability of data and materials}

All the raw data supporting the findings can be requested from Dr. Somi G, Head of the Epidemiology Unit of the National AIDS Control Programme (NACP).

\section{Authors' contributions}

GS, JN, SV, TJ were involved for preparing the study protocol. GS was the overall coordinator of the study, while JN, SV and TJ performed statistical analyses. MIM, MM, JM and AJ were involved in various stages of study from reviewing the protocol, reviewing the results and preparation of the manuscript. All authors jointly prepared the final manuscript. All authors read and approved the final manuscript.

\section{Ethics approval and consent to participate}

This data is originating from routine services of health facilities that are providing HIV care and treatment services in Tanzania using the National Guidelines for HIV Care and Treatment, in which ethical issues are strongly advocated. The Ministry of Health, Community Development, Gender, Elderly and Children (MoHCDGEC) through the National AIDS Control Programme (NACP) coordinate these facilities and provided ethical approval to analyse the data.

\section{Consent for publication}

Not applicable.

\section{Competing interests}

The authors declare that they have no competing interests.

\section{Publisher's Note}

Springer Nature remains neutral with regard to jurisdictional claims in published maps and institutional affiliations.

\section{Author details}

${ }^{1}$ National AIDS Control Programme, Ministry of Health, Community Development, Gender, Elderly and Children, Mwanza, Tanzania. ${ }^{2}$ Department of Microbiology and Immunology, School of Medicine, Muhimbili University of Health and Allied Sciences, Mwanza, Tanzania. ${ }^{3}$ London School of Hygiene and Tropical Medicine and National Institute for Medical Research (NIMR), Mwanza, Tanzania.

Received: 22 December 2016 Accepted: 1 August 2017

Published online: 07 August 2017

\section{References}

1. GBD2015 HIV Collaborators. Estimates of global, regional, and national incidence, prevalence, and mortality of HIV, 1980-2015: the global Burdenof disease study 2015. Lancet HIV 2016; 3: e361-e387 Published Online 19 July 2016 http://dx.doi.org/10.1016/\$2352-3018(16)30087

2. WHO. Consolidated guidelines on the use of antiretroviral drugs for treating and preventing HIV infection: what's new? November, 2015. Available at http:// www.who.int/hiv/pub/arv/policy-brief-arv-2015/en/ (accessed 6 May 2016).

3. Newell M, Brahmbhatt $H$, Ghys PD. Child mortality and HIV infection in Africa: a review. AIDS. 2004;18(suppl 2):S27-34

4. The United Republic of Tanzania. Ministry of Health and social welfare National AIDS control programme. National Guidelines for the management of HIV and AIDS; 2015. https://aidsfree.usaid.gov/sites/default/files/04_11_ 2016.tanzania_national_guideline_for_management_hiv_and_aids_may_ 2015._tagged.pdf

5. World Health Organisation. Towards universal access. Scalling up priority HIV/AIDS interventions in the health sector. Progress report 2010. http:// www.who.int/hiv/pub/2010progressreport/summary_en.pdf?ua=1.

6. Piot $P$, Abdool Karim SS, Hecht R, et al. Defeating AIDS_advancing global health. Lancet. 2015;386:171-218.

7. UNAIDS. 90-90-90-anambitioustreatmenttargettohelpendthe AIDS epidemic. Oct 8, 2014. http://www.unaids.org/en/resources/documents/ 2014/90-90-90(accessed 6 May 2016)

8. UNAIDS. Onthefast-tracktoend AIDS. UNAIDSstrategy 2016-2021.Aug 10, 2015. http://www.unaids.org/en/resources/documents/2015/UNAIDS_ PCB37_15-18 (accessed 6 May 2016).

9. United Republic of Tanzania. Ministry of Health and Social Welfare. National Aids Control Programme. Third Health Sector HIV and AIDS Strategic Plan (HSHSP III) 2013-2017 http://ihi.eprints.org/2291/1/HSHSP III 2D Final Draft 15SEP2013 final_output_to_NACP_with NBTS_update 04112013.

10. The United Republic of Tanzania. National Strategy for Growthand Reductionof Poverty II NSGRP || http://www.international.gc.ca/ development-developpement/assets/pdfs/countries-pays/national-strategyfor-growth-and-reduction-of-poverty-tanzania.pdf

11. UN Sustainable Development Goals. http://www.undp.org/content/undp/ en/home/sustainable-development-goals.html

12. Stata Corp. 2015. Stata statistical software: release 14. College Station, TX: Stata Corp LP). 
13. World Health Organization. Clinical guidance across the continuum of care: antiretroviral therapy. http://www.who.int/hiv/pub/guidelines/arv2013/art/ arv2013_chapter07_low.pdf

14. Madec Y, Boufassa F, Avettand-Fenoel V, Hendou S, Melard A, Boucherit S, Surzyn J. Meyer Rouzioux C; ANRS SEROCO/HEMOCO study group early control of HIV-1 infection in long-term non-progressors followed since diagnosis in the ANRS SEROCO/HEMOCO cohort. J Acquir Immune Defic Syndr. 2009;50(1):19-26. doi:10.1097/QAl.0b013e31818ce709.

15. Kim AA, Mukui I, N'gan'ga $L$, et al. Progress in reversing the HIV epidemic through intensified access to antiretroviral therapy: results from a nationally representative population-based survey in Kenya, 2012. PLoS One. 2016;11: e0148068.

16. Matida $L H$, Marcopito $L F$, Succi RC,etal. Improving survival among Brazilian children with perinatally-acquired AIDS Braz J Infect Dis 2004; 8:419-423.

17. Song $R$, Jelagat J, Dzombo $D$, et al. Efficacy of highly active antiretro- viral therapy in HIV-1-infected children in Kenya. Pediatrics. 2007;120:e856-61.

18. Wamalwa DC, Farquhar C, Obimbo EM, et al. Early response to highly active antiretroviral therapy in HIV-1-infected Kenyan children. J Acquir Immune Defic Syndr. 2007:45:311-7.

19. Violari A, Cotton MF, Gibb DM, et al. Early antiretroviral therapy and mortality among HIV-infected infants. N Engl J Med. 2008;359:2233-44

20. Patel $K$, Hernan MA, Williams $P L$, et al. Long-term effectiveness of highly active antiretroviral therapy on the survival of children and adolescents with HIV infection: a 10-year follow-ups tudy. Clin Infect Dis. 2008;46:507-15.

21. Chiappini E, Galli L, Tovo PA, et al. Five-year follow-up of children with perinatal HIV-1 infection receiving early highly active antiretroviral therapy. BMC Infect Dis. 2009;9:140,

22. Dollfus C, Le Chenadec J, Faye A, et al. Long-term outcomes in adolescents perinatally infected with $\mathrm{HIV}-1$ and followed up since birth in the French perinatal cohort (EPF/ANRSCO10). Clin Infect Dis. 2010;51:214-24.

23. Edmonds $\mathrm{A}$, Yotebieng $\mathrm{M}$, Lusiama J, et al. The effect of highly active antiretroviral therapy on the survival of HIV-infected children in a resourcedeprived setting: a cohort study. PLoS Med. 2011;8:e1001044.

24. McConnell MS, Byers RH, Frederick T, et al. Trends in antiretroviral therapy use and survival rates for a large cohort of HIV-infected children and adolescents in the United States,1989-2001. J Acquir Immune Defic Syndr. 2005;38:488-94.

25. Williams PL, Van Dyke R, Eagle M, et al. Association of site-specific and participant-specific factors with retention of children in a long-term pediatric HIV cohort study. Am J Epidemiol. 2008;167:1375-86.

26. Braitstein P, Katshcke A, Shen C,etal. Retention of HIV-infected and HIVexposed children in a comprehensive HIV clinical care programme in western Kenya. Tropical Med Int Health. 2010; 15:833-841.

27. Anaky MF, Duvignac J, Wemin L, et al. Scaling up antiretroviral therapy for HIV-infected children in Côted'Ivoire: determinants of survival and loss to programme. Bull World Health Organ. 2010;88:490-9.

28. Hassan AS, Sakwa EM, Nabwera HM, et al. Dynamics and constraints of early infant diagnosis of HIV infection in rural Kenya. AIDS Behav. 2012;16:5-12.

29. Barth RE, Tempelman HA, Moraba R, et al. Long-term outcome of an HIVtreatment programme in rural Africa: viral suppression despite early mortality. AIDS Res Treat. 2011;2011:ID434375.

30. Sutcliffe CG, Bolton-Moore C, van Dijk JH, et al. Secular trends in pediatric antiretroviral treatment programs in rural and urban Zambia: a retrospective cohort study. BMC Pediatr. 2010;10:54.

31. Davies MA, Keiser O, Technau K, et al. Outcomes of the south African National Antiretroviral Treatment Programme for children: the leDEA southern Africa collaboration. S Afr Med J. 2009:99:730-7.

32. Mate KS, Bennett B, Mphatswe W, et al. Challenges for routine health system data management in a large public programme to prevent motherto-child HIV transmission in South Africa. PLoS One. 2009;4:e 5483.

33. Kiragga AN, Castelnuovo B, Schaefer P, et al. Quality of data collection in a large HIV observational clinic database in sub-Saharan Africa: implica- tions for clinical research andauditofcare. J Int AIDS Soc. 2011;14:3.

34. Garrib A, Stoops N, MCKenzie A, et al. An evaluation of the district health information system in rural South Africa. S Afr Med J. 2008;98:549-52.

\section{Submit your next manuscript to BioMed Central and we will help you at every step:}

- We accept pre-submission inquiries

- Our selector tool helps you to find the most relevant journal

- We provide round the clock customer support

- Convenient online submission

- Thorough peer review

- Inclusion in PubMed and all major indexing services

- Maximum visibility for your research

Submit your manuscript at www.biomedcentral.com/submit

) Biomed Central 